\title{
Sobre o peso de si e maestrias \\ uma análise de parte da cena atual da canção popular brasileira
}

\author{
Carlos Augusto Bonifácio Leite ${ }^{1}$
}

\section{Resumo}

Este artigo trata de uma parte da cena atual da canção popular brasileira, comparando artistas cuja produção se iniciou nos anos 1960, e que seguem lançando trabalhos inéditos - Chico Buarque e Caetano Veloso - a artistas cujos primeiros trabalhos autorais foram lançados recentemente - Siba, Apanhador Só e Juçara Marçal. Neste cotejo, este texto busca identificar algumas transformações na produção dos primeiros e traçar semelhanças entre as estéticas destes últimos. No horizonte, se vislumbram os efeitos de maturação da indústria cultural para a canção popular no Brasil.

\section{Palavras-chave}

Canção popular, indústria cultural, contemporaneidade.

1 Universidade Federal do Rio Grande do Sul (UFRGS, Porto Alegre, Rio Grande do Sul, Brasil). 


\title{
About the Weight of Being Yourself and Masteries \\ an Analysis of the Current Brazilian Popular Music Scene
}

\author{
Carlos Augusto Bonifácio Leite
}

\begin{abstract}
This article is about a fraction of the current Brazilian popular music scene, comparing artists whose output began in the 1960's and continue releasing original material - Chico Buarque and Caetano Veloso - to artists whose early works were recently released - Siba, Apanhador Só and Juçara Marçal. In this comparison, this text aims to identify some changes in the Chico's and Caetano's output and to trace aesthetic similarities between the more recent songwriters. From this discussion, one may glimpse the effects of the development of the culture industry on Brazilian popular song.
\end{abstract}

Keywords

Popular song, culture industry, contemporaneity. 


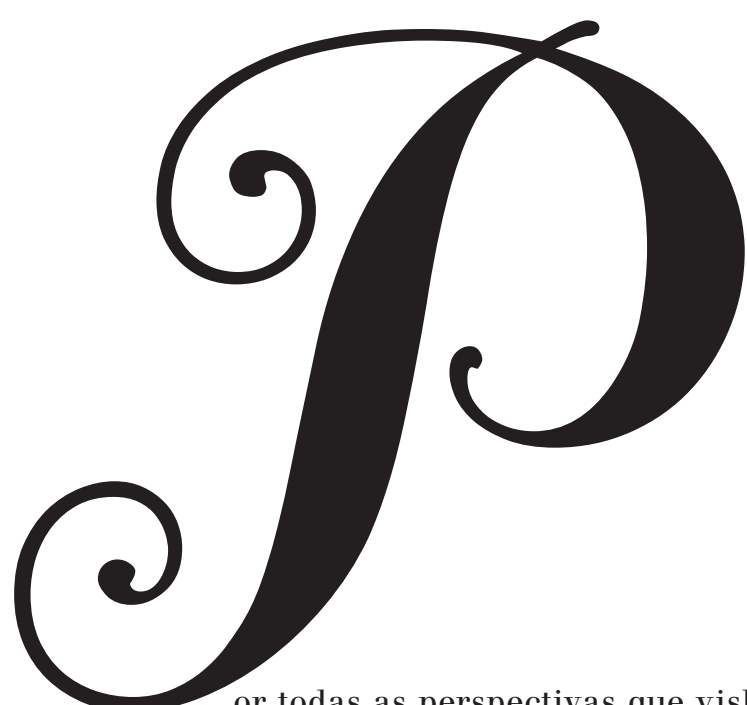

or todas as perspectivas que vislumbro, este ensaio é um salto no abismo. Sua vertigem é divisar a cena contemporânea da canção popular brasileira cujos acentos se dão nas práticas de hiperconsumismo e da ubiquidade da internet, a partir da delimitação de dois grupos: o primeiro, representado pelos cancionistas Chico Buarque e Caetano Veloso, que chegaram ao centro da cena nos festivais de música popular dos anos 1960 e que ainda lançam, quase cinquenta anos depois, álbuns autorais inéditos; o segundo, de cancionistas que surgiram para o grande público na última década e que já são observados pela crítica e pela academia com interesse, aqui exemplificados por Siba, a banda de rock Apanhador Só e Juçara Marçal ${ }^{2}$.

Aos sacerdotes da tradição pode parecer descabido alinhar artistas tão desiguais em termos da extensão de suas trajetórias no cancioneiro popular e do alcance de suas realizações estéticas. Para esses mediadores, haveria uma divisão da cena contemporânea, seja da canção popular, seja de outros gêneros, entre artistas que já teriam mostrado a que vieram, e, portanto, estariam desobrigados de seguir sendo criativos, e aqueles que ainda precisariam mostrar a que vieram, sem ter sido definitivamente validados pela obra criada até então. Distancio-me dessa postura, ao propor que, independente da celebração merecida pela pertença ao cânone da canção popular brasileira, todos sempre precisam mostrar a que vêm quando produzem obras inéditas, não podendo se escorar em suas trajetórias a não ser que se neguem a seguir produzindo,

2 Juçara Marçal, como intérprete que assina a proposta estética de seu mais recente trabalho autoral - mobilizo uma expansão prevista por Tatit para a noção de "cancionista”, in TATIT, Luiz. O cancionista. 2. ed. São Paulo: Edusp, 20o2, p.10. 
o que é mais comum do que gostaríamos - a sombra ou o peso das trajetórias, aliás, terá considerável importância neste trabalho. Ser artista é estar na arena, e, por isso, há interesse e proveito na aproximação dessas duas colunas.

Na consideração da canção popular como processo social decantado e observando as condições materiais em que produziam aqueles artistas há cinquenta anos e como esses mesmos artistas produzem hoje, em cotejo com o lugar ocupado pelo segundo grupo na atual indústria cultural, grupo que se caracteriza por não manter contrato com gravadoras, ter um traço profundamente pessimista em suas dicções e serem autores de notável grau de complexidade, creio que seja possível divisar alguns traços da cena contemporânea e flagrar a manifestação peculiar de um dos paradoxos do nosso tempo quanto à produção cancional. Este é o objetivo do presente ensaio.

O surgimento de Chico Buarque e Caetano Veloso é resultado de um conjunto de fatores bastante favorável à canção popular existentes na segunda metade da década de 1960. A formação, em termos candidianos, da canção popular urbana e em moldes modernos nos anos $1930^{5}$, tornando-a linguagem estética disponível e consumida pela classe média, o processo modernizador promovido pela Bossa Nova a partir de 1958, e que permitiu recuperar a tradição da canção em novo patamar, o crescente mundo universitário brasileiro dos anos 1960, o surgimento da televisão como nova mídia hegemônica - hegemonia que se consolidaria na década seguinte - e mesmo a maneira como o governo militar reprimiu primeiramente aqueles que faziam política em cais e fábricas, dando certo tempo aos contestadores agentes de cultura ${ }^{4}$, são todos ingredientes que explicam a conjuntura que forjou os festivais de música popular naqueles anos, plataforma inicial destes dois compositores.

Ao filho de Sérgio Buarque de Holanda, após as participações destacadas nos festivais, coube desenvolver uma dicção que prima pela

3 LEITE, Carlos Augusto Bonifácio Leite. Catulo, Donga, Sinhô e Noel: o processo de formação da canção popular urbana brasileira. 2011. 157 f. Dissertação (Mestrado) Universidade Federal do Rio Grande do Sul. Porto Alegre-RS. 2011 [não publicada].

4. SCHWARZ, Roberto. Cultura e política 1964-1969. In: O pai de família e outros estudos 2. ed. Rio de Janeiro: Paz \& Terra, 1992, p.62. 
profundidade $^{5}$ e que percorre uma gama impressionante de formas e de temas, ocupando, no campo da canção, uma importância correlata à que Carlos Drummond de Andrade assume para a poesia, uma voz central na produção de uma forma estética em determinada cultura. Noutros termos, todo cancionista refletido passa pela produção de Chico Buarque, mesmo que para negá-la, seja por sua condição de mestre da forma cancional - não se mobiliza aqui, necessariamente, a formulação de Pound", embora seja adequada, mas compreende-se "mestre" como um artista para o qual certa linguagem não mais apresenta segredos -, seja por sua condição de intérprete do Brasil, assumida ao longo da década de 70, pelas faixas de seus discos. A herança da alcunha de "intérprete do Brasil" do sociólogo e intelectual de ponta para o imberbe cancionista, que depois enveredará para os caminhos do drama e do romance, não deixa de ser a materialização do acerto da tese do Holanda pai, ao que se soma a possibilidade forte de a dicção do Holanda filho ser permeada de certa "utopia cordial", a "imbricação do plano coletivo (político) e do plano individual (erótico)".7

Ao filho de Dona Canô, ele, também figura importante nos festivais, mas menos vitoriosa a princípio, coube capitanear o movimento tropicalista, concretizado no álbum Tropicalia ou panis et circencis $(1968)^{8}$. Estética cancional inovadora no deslocamento da crítica dos temas abordados para seus elementos constitutivos ${ }^{9}$, foi especialmente inflamável ao pôr em questão os modos de organização da vida burguesa - família, religião, trabalho e ordem - em tempo que estes valores estavam sendo resguardados pela ditadura armada desde o golpe de $1964^{10}$. Caetano Veloso estrutura o tropicalismo como a autoproclamada ponta de lança da linha evolutiva da canção popular brasileira, assumindo a missão de

5 TATIT, Luiz. O cancionista., p.234.

6 POUND, Ezra. ABC da Literatura; organização e apresentação da edição brasileira Augusto de Campos; tradução de Augusto de Campos e José Paulo Paes. 11. ed. São Paulo: Cultrix, 2006, p.42.

7 GARCIA, Walter. Melancolias, mercadorias: Dorival Caymmi, Chico Buarque, o Pregão de Rua e a Canção Popular-Comercial no Brasil. Cotia, SP: Ateliê Editorial, 2013, p.215.

8 Em aula-espetáculo por comemoração dos 80 anos da UFRGS, em 04/05/2014, Gilberto Gil frisou a centralidade de Caetano Veloso na organização e na feitura do disco, da concepção do projeto ao convite e à motivação dos artistas. VELOSO, C., GIL, G. et alii. Tropicalia ou panis et circencis. Produzido por Manoel Barenbein. Philips, 1968.

9 FaVARetTo, Celso. Tropicália: Alegoria, Alegria. 3. ed. Cotia, SP: Ateliê Editorial, 2000, p.21.

1o SCHWARZ, Roberto. Cultura e política 1964-1969, p.77. 
vanguarda reiterada do gênero cancional, a quem sempre, ainda nos dias de hoje, se recorre com a pergunta: o que há de novo?

A síntese breve, quase criminosamente breve, dos dois prováveis principais cancionistas brasileiros da segunda metade do século XX é importante para notarmos que sobre eles repousam expectativas muito distintas da parte do público que os aprecia. Por mais que, obviamente, haja grande força de inovação em Chico Buarque - a mobilização da linguagem do rap em "Subúrbios" e "Ode aos ratos", ambas em Carioca $(2006)^{11}$, são indícios disso - e reconheça-se o intérprete do Brasil e a maestria de Caetano em diversas canções - "Estou triste", in Abraçaço $(2012)^{12}$, é uma obra-prima da representação entoativa da tristeza profunda, em sua cadência grave e repetitiva, com direito ao esmero poético de "Eu me sinto vazio / E ainda assim farto / Estou triste tão triste / E o lugar mais frio do Rio é o meu quarto", que constrói uma série de rimas naturais internas e externa (vazio/frio/Rio e farto/lugar/ quarto) ${ }^{13}$-; creio que não exagero ao dizer que a recepção contemporânea desses cancionistas tende a esperar o magistral intérprete do Brasil em Chico Buarque e o incansável inovador em Caetano Veloso, ora se vendo recompensada, ora decepcionada. As maneiras distintas como se materializa nos álbuns a diferença ao lidar com essas expectativas começa a desvelar uma questão intrigante sobre suas atuais produções.

Por este caminho, ouvir Chico $(2011)^{14}$ é encontrar ali a excelência que o consagrou como o mais virtuoso cancionista brasileiro dos últimos cinquenta anos. No referido álbum, a riqueza da dicção do cancionista $^{15}$ assombra, ao passear por blues, sambas, baião e outros gêneros, bem como seu perfeccionismo técnico, que esbanja habilidade figurativa e poética, por exemplo, em "Sou eu", ao ouvirmos nitidamente o eu cancional, “dono da mulher" que samba, se gabar pelo domínio que exerce, em "Nina", capaz de rimas como "toca/vodka", e em "Essa pequena", com brincadeiras semânticas sofisticadas (penar / pena /

11 BUARQUE, Chico. Carioca. Produção de Luiz Claudio Ramos. Rio de Janeiro: Biscoito Fino, 2006.

12 VELOSO, Caetano. Abraçaço. Produzido por Moreno Veloso. São Paulo: Universal, 2012.

13 Interessantemente, há uma canção siamesa, "Sem você 2 " no CD Chico.

14 BUARQUE, Chico. Chico. Produção de Luiz Claudio Ramos. Rio de Janeiro: Biscoito Fino, 2011.

15 As noções de "dicção", "figurativização" e outras são oriundas das proposições de Luiz Tatit, mormente em $O$ cancionista. Embora pouco atenta às relações entre sociedade e forma cancional, a obra de Tatit é pressuposto de todo o trabalho, como plataforma que promove uma visada privilegiada da canção em suas especificidades semióticas. 
pequena) - "artesanato sonoro" já observado por Walter Garcia em artigo no prelo ${ }^{16}$.

Nesse mesmo texto, Walter Garcia aponta para a predominância de dois temas no álbum: "o da herança da sociabilidade brasileira formada durante o predomínio da economia agrário-exportadora" e o "da ordem do lirismo amoroso nos dias atuais", ao que modulo um pouco, a partir da perspectiva de alguém cujos valores foram formados noutros tempos, no "antigamente", o que resulta tanto na beleza perfeita da representação da angústia de se amar alguém mais novo, de "Essa pequena", quanto no machismo mais ou menos charmoso, mais ou menos evidente, de "Sou eu". Avançando mais, também é possível o resultado ambivalente de "Nina”, uma canção sublime na escolha de imagens e na minúcia da construção, mas que expressa a condição de alguém para quem amar virtualmente e à (muita) distância uma russa das mais sagazes só pode resultar mesmo em melancolia e alcoolismo, e não em possibilidades suficientemente concretas de afeto.

No entanto, mais do que nas canções do amante renitente, nas quais a maestria de Chico segue recompensadora, é nas canções do intérprete do Brasil que recaem as atenções deste ensaio. A perspectiva assumida pelo eu da canção parece se aproximar da visão de quem perscruta os fenômenos a partir da velhice, espreitado pela morte na curva do rio ("Querido diário") e que estiliza de maneira meio canhestra a gíria da amante mais nova (“Tipo um baião") - até quando o assunto se centra no amor, como visto, observa-se uma tensão análoga. É tentador concluir que, no tipo particular de performance que é o gesto na canção popular, a possibilidade de interpretação do país seja construída preferencialmente a partir de um eu cancional maduro, mas talvez não demasiado maduro, como o que propõe o cancionista. Quando Chico opta por um ethos idoso, as sínteses de Brasil são também vistas com desdém e enfado, como uma tarefa de moços, ao passo que o cancionista habilmente erige uma voz que depura com sofisticação os grandes sentimentos: o amor, a tristeza, o medo da morte, os ciúmes etc. Se, porventura, o cancionista ainda se incumbe da reconstrução crítica da história, como em "Sinhá", o descompasso é patente e os equívocos são muitos, da oscilação rude entre um e outro narrador à apropriação explícita do olhar do escravo pelo misticismo patriarcal da casa-grande ("Estava lá na roça / Sou de olhar ninguém / Não tenho mais cobiça / Nem enxergo bem”).

I6 GARCIA, Walter. Elementos para a crítica do disco Chico (2011). In: GARCIA, Tânia da Costa \& FENERICK, José Adriano (org.), História e Música. São Paulo: Alameda Editorial, no prelo. 
Se em Chico nos depararíamos com um velho mestre que parece abdicar aos poucos do legado paterno, Caetano Veloso faz fogo da reafirmação constante de um ethos jovem em seus mais recentes trabalhos: Cê (2006) $)^{17}$, Zii e Zie (2009) ${ }^{18}$ e Abraçaço. O óbvio, mas que precisa ser enunciado, é que o cancionista não largou o osso, nem a boquinha, de seguir de posse do uniforme de herói da vanguarda da canção popular brasileira ${ }^{19}$ e para isso intensifica sua relação com músicos mais novos, de sonoridade relativamente inovadora, e até mesmo cunha criticamente novas classificações para o que vem produzindo ("trans-rock" e "transsamba”, jogando nos dois times, o da produção e o da crítica.

O menos evidente é a condição passiva do cancionista diante desse processo que aparenta e busca ser figura de proa. Adorno já observou que, no panorama moderno, "o consumidor não é rei, como a indústria cultural gostaria de fazer crer, ele não é o sujeito dessa indústria, mas seu objeto". ${ }^{20}$ Pode-se desdobrar essa afirmação para os autores/produtores ou, ao menos, questionar sua condição de quem frequenta ileso as estruturas do mercado da música popular (e as explode por dentro, como o brado do discurso célebre). Nesse sentido, proponho uma posição antípoda à observação de Tatit quanto à capacidade de Caetano em reverter as expectativas e obedecer somente aos impulsos de criação ${ }^{21}$, embora parta de outra observação do mesmo crítico para tentar entender a produção atual do cancionista.

Tatit afirma que "os fatos do mundo exterior frequentam as canções de Caetano apenas ao adquirirem valor subjetivo e nunca ultrapassam essa medida". ${ }^{22}$ Não só a dicção de Caetano está fortemente centralizada na exuberância do eu, como também encontramos outros exemplos dessa "medição do mundo pela régua subjetiva" em suas memórias, Verdade tropical ${ }^{23}$ - em que, para além da anedota infantil da descoberta de que só há mundo a partir do eu, nada é surpresa para o narrador e tudo já havia sido feito antes, na Bahia -, no documentário Coração

17 VELOSO, Caetano. Cê. Produzido por Kassin. São Paulo: Universal, 2006.

18 VELOSO, Caetano. Zii e zie. Produzido por Moreno Veloso e Pedro Sá. São Paulo: Universal, 2009.

19 O mito da Górgona costumava nos ensinar o preço a ser pago pelo herói vaidoso, a suplantação do ser por sua imagem - proposição rica de sentidos neste trabalho e no mundo contemporâneo.

20 ADORNO, Theodor W. A indústria cultural. In: COHN, Gabriel (org.) Comunicação e indústria cultural. São Paulo: Companhia Editora Nacional, 1977, p. 287-288.

21 TATIT, Luiz. O cancionista, p.2z6.

22 Idem, ibidem.

23 VELOSO, Caetano. Verdade tropical. São Paulo: Companhia das Letras, 2008. 
vagabundo ${ }^{24}$ - em que Caetano aparece ratificando a semelhança, notada antes por Moreno, entre Nova Iorque e Santo Amaro (na aula-espetáculo de Gilberto Gil já citada, o compositor recordou que Caetano, quando conheceu Jimi Hendrix na Inglaterra, comentou a semelhança entre o guitarrista estadunidense e os baianos negros e esguios) - ou em suas resenhas atuais no jornal $O$ Globo - em que frequentemente objeta os críticos que não entenderam o que ele quis dizer com tal canção ou saúda os que mataram a charada embutida em sua arte.

Não é simples analisar materialmente as contradições do eu hipertrofiado da dicção de Caetano Veloso e como isso se manifesta em Abraçaço. O comentário mais comum diz respeito a uma suposta vaidade do cancionista, mas o que pode parecer extremamente agressivo pela referência à biografia, pelo argumento ad hominem, é, com efeito, uma crítica amena, ao não contemplar as razões históricas do problema, que passam pela encarnação xamã do vanguardista, impulsionado por um ambiente capaz de reificar todas as esferas, em que o sujeito poderia figurar como casamata da autenticidade artística, último reduto da "aura" 25 em um mundo dominado por uma indústria cultural rápida e agressiva.

A saída utópica do eu, que ganha ares de retorno ao primitivo no começo da carreira do cancionista, estende-se à sua criação e encontramos no mais recente trabalho um álbum que oscila preponderantemente entre falar de si e falar do tropicalismo, direta ou indiretamente - falar do tropicalismo, em parte, é um modo de falar de si. Para que não pensem arbitrária minha colocação, os exemplos são muitos: em "Abraçaço", fala de si e do tropicalismo, em diálogo entoativo com "Eclipse oculto" e temático com "Aquele abraço"; em "Estou triste", a canção constrói o lugar do gênio depressivo, que sente o mundo mais do que os outros; em “O império da lei”, há a fusão tropicalista dos ritmos rumo ao interior do país; em "Funk melódico", a fusão tropicalista de ritmos rumo à periferia das cidades; em "Vinco", uma canção romântica cujos versos que encerram cada uma das partes são quatro repetições do termo "de mim" e quatro do termo "eu"; e em "Parabéns", um e-mail pessoal habilmente trabalhado pelo cancionista para se tornar canção. (Dentre as possíveis exceções, destaque para "Um comunista", recuperação afetiva da história de Carlos Marighella, mas que contém os seguintes versos "O baiano morreu / Eu estava no exílio / Eu mandei

24. ANDRADE, Fernando Grostein. Coração vagabundo. Documentário, Brasil, 2009.

25 BENJAMIN, Walter. Obras escolhidas, volume I: magia e técnica, arte e política. 3. ed.; tradução: Sérgio Paulo Rouanet. São Paulo: Editora Brasiliense, 1987, p.167. 
um recado / 'Eu que tinha morrido / E que ele estava vivo"'). Todas, vale dizer, absolutamente todas, maravilhosas canções!

Reservei, para uma análise mais detida, por sua sinuosidade, "A Bossa Nova é foda". Salvo melhor leitura, esta canção representa bem alguns impasses decisivos da obra atual de Caetano Veloso. A um ouvido desatento, poderia parecer altruísta o elogio à escola de Jobim, Vinícius \& João, contudo, trata-se de recurso argumentativo conhecido, de elogio indireto, do tipo: bom não sou eu, bom é meu mestre. Estando a síntese colocada no ponto mais baixo, mais grave, do plano entoativo, o verso "A Bossa Nova é foda", que intitula a canção, é emitido como asserção indiscutível. E se meu mestre é foda, indiscutivelmente foda...

Há também um conjunto de signos mais ou menos cifrados (todo hermetismo tem um quê de descalabro subjetivo?), que vão de "restos de rabada", "ergométricas", "o bardo judeu romântico de Minessota” (Bob Dylan), "magno instrumento antigo" (Carlos Lyra), "bruxo de Juazeiro" (João Gilberto) - os artistas não são nomeados na canção, somente os lutadores -, à impressão ingênua de que "Lá fora o mundo se torce para encarar a equação". Adorno já advertira que:

Se a tendência social objetiva da época se encarna nas intenções subjetivas dos diretores gerais, são estes os que integram os setores mais poderosos da indústria: aço, petróleo, eletricidade, química. Os monopólios culturais são, em comparação com estes, débeis e dependentes [grifo meu]. ${ }^{26}$

O que nos faz concluir que o mundo não se torce lá fora para encarar a equação, o mundo segue o ritmo dos negócios, independentemente da trilha sonora que esteja ao fundo - não raras vezes, inclusive, a Bossa Nova ocupa essa função de trilha sonora do mundo cosmopolita.

De todas as questões, no entanto, a mais desconfortável em relação à atual dicção de Caetano me parece ser a reutilização de um recurso que causou estrondo em 1967, mas que agora soa mais como um referendo a um estado de reificação do que sua impugnação. Em "Alegria, alegria" lá estão os famosos versos "Eu tomo uma coca cola / Ela pensa em casamento / Uma canção me consola”, em que o alinhamento da bebida industrializada, da instituição burguesa e da criação artística põe em xeque o distanciamento entre as três "coisas", suas particularidades,

26 ADORNO, Theodor W. Indústria cultural e sociedade; seleção de textos Jorge Mattos Brito de Almeida; traduzido por Juba Elisabeth Levy [et alii]. 5. ed. São Paulo: Paz e Terra, 2009, p.7. 
e apresenta-se como possibilidade, talvez demasiado drástica, talvez demasiado utópica, de revolução, mediante a acusação de um mundo para o qual tudo é produto, tudo é objeto e pode ser vendido.

Em 2012, quando o recurso é repetido, lutadores de MMA e a estética que supostamente "transformou o mito das raças tristes" são, de fato, produtos em um mercado ubíquo e voraz, em que aqueles são mais valorados do que esta, inclusive. A formulação de Caetano tende a ser sinal de reificação da própria forma estética, o tropicalismo, e faz questionar o quanto não há de fetiche na mobilização exagerada do filtro subjetivo para cantar o mundo, uma reificação do eu, a transformação de Caetano em sua própria estátua.

(Vale a nota de que o cancelamento do show de João Gilberto em Porto Alegre em 2011 - o motivo alegado foi uma forte gripe, mas se sabe que o motivo real foi o preço exorbitante dos ingressos, não abraçado pelo público consumidor - concomitante aos primeiros e bem-sucedidos eventos de MMA na cidade não deixa de ser uma piada macabra das circunstâncias na periferia da periferia do capitalismo).

Até aqui procurei perscrutar a maneira com que dois dos maiores cancionistas da nossa história lidam com a longevidade de suas dicções. A hipótese é de que, magistralmente, ambos sigam produzindo canções impecáveis, embora pese sobre a recepção e a produção de Chico Buarque o fardo de intérprete do Brasil e sobre a recepção e a produção de Caetano Veloso o fardo da eterna juventude criadora - ambas construções feitas há pelo menos quatro décadas a respeito de suas obras e que resistem até hoje. Ao propor que influam em suas criações, não pretendo analisar qualquer agrura pessoal ou angústia, mas o resultado estético obtido, a partir da tradição, em especial a tradição de suas obras pregressas sobre suas obras atuais. Não creio também que seja absurdo defender que somente os "completamente desligados" podem adquirir um CD de um dos dois com os mesmos anseios que comprariam a obra de um artista recente no mercado - há, portanto, ainda, uma tradição de recepção a ser considerada.

Em contraste ao range-rede merecido dos nossos dois canônicos cancionistas, surge na cena da canção contemporânea brasileira, a partir da internet e não mais da televisão, em um mundo em que de fato é possível comprar uma Coca-Cola, um casamento ou uma canção, e 
tudo de casa, um grupo interessante de artistas que busca interpretar este entorno de uma condição mais incômoda, mas não dotados (ainda, talvez...) de maestria análoga à de Chico ou de Caetano. Dentre esses novos artistas, destaco o recifense Siba, ex-integrante da banda Mestre Ambrósio, que lançou seu segundo CD solo, Avante ${ }^{27}$, em 2012; os porto -alegrenses da Apanhador Só, autores de quatro trabalhos autorais, sendo Antes que tu conte outra, de $2013^{28}$, o mais recente; e a paulistana Juçara Marçal, uma das componentes do trio Metá Metá, intérprete que lançou o primeiro disco solo, Encarnado, em $2014^{29}$ - não é fortuito que os três tenham produzido independentemente seus trabalhos, fora do universo das gravadoras, e que disponham gratuitamente os álbuns para download.

Além da condição material relativamente insegura em que todos vivem - sendo mais preciso, nenhum desses artistas poderia deixar de trabalhar para viver de direitos autorais, como Chico e Caetano (a Apanhador Só, que conheço mais de perto, não recebeu da música sequer sua autonomia financeira plena) -, duas características parecem unir de maneira reveladora esses três artistas.

As dicções de Siba, da Apanhador Só e de Juçara Marçal são certamente mais disfóricas do que eufóricas, construindo certo tom de ruína, de desamparo, de desacerto, de poucas saídas em vista - afastando-se, por essa característica, da dicção de Caetano em Abraçaço, por exemplo. Embora este traço percorra os álbuns de ponta a ponta, podemos exemplificá-lo nos versos que abrem cada um dos trabalhos: "Não vejo nada que não tenha desabado / Nem mesmo entendo como estou de pé / Olhando um outro num espelho pendurado / Me reconheço, mas não sei quem é" ("Preparando o salto", Siba, em Avante); "Essa balela aqui não vai colar / Não tá tão fácil assim de convencer" ("Mordido", de Alexandre Kumpinski, em Antes que tu conte outra) - essas duas canções entoadas bem próximo à curva prosódica, em chave de figurativização -; e “Não diga que estamos morrendo / Hoje não" ("Velho amarelo", Rodrigo Campos, em Encarnado). Neste último caso, em chave passional, o impasse é mais nuançado: estamos morrendo, mas não o diga hoje, ou

27 SIBA. Avante. Produção de Fernando Catatau. Independente, São Paulo, 2oı. O álbum pode ser obtido gratuitamente em http://mundosiba.com.br/downloads. Acesso em: 27 jun. 2014 .

28 APANHADOR SÓ. Antes que conte outra. Independente, Porto Alegre, 201z. O álbum pode ser obtido gratuitamente em http://www.apanhadorso.com/. Acesso em: 27 jun. 2014.

29 MARÇAL, Juçara. Encarnado. Independente, São Paulo, 2o14. O álbum pode ser obtido gratuitamente em http://www.jucaramarcal.com/. Acesso em: 27 jun. 2014. 
hoje não diga que estamos morrendo? De todo modo, parece paradigmático que três artistas de lugares e formações distintas, a serem retomadas adiante, formulem um prognóstico bastante negativo a respeito do estado de coisas. Não se trata do desencanto maduro expressado nas canções de Chico comentadas aqui, exemplificado também na vacilação da memória de "Barafunda" (Ivan Lins \& Chico Buarque), mas da expressão de quem busca ativamente uma saída razoável sem conseguir vislumbrá-la.

Também une os três cancionistas uma textura ou sonoridade que tenciona, provoca, distende, e não harmoniza, conjuga, comunga com o que está sendo entoado - afastando-os igualmente, portanto, da produção voltada para ir ao encontro do "gosto médio" ou para fundá-lo, o que seria a marca de uma produção pop ou mainstream. A canção de abertura de Avante, de Siba, "Preparando o salto" traz compassos compostos, ou seja, seus ciclos de regularidade se constroem a partir de tempos ímpares, desacomodando o ouvinte e distanciando-se do que se espera de uma canção pop. De maneira análoga, Juçara Marçal, na canção que abre Encarnado, "Velho amarelo", começa a entoar a letra em certo contraponto com a guitarra que descerra o álbum - e mais próxima a uma segunda guitarra que só entra no arranjo um pouco adiante.

Talvez o exemplo mais evidente seja o da banda Apanhador Só, que desenvolveu nos últimos trabalhos o que chamam de "estética sucateira". A partir de panelas, latas de manteiga, para-lamas de bicicleta e outros "inutensílios" - cito alguns dos instrumentos referenciados no encarte -, além de técnicas específicas, como o circuit bending ${ }^{30}$, o grupo conseguiu construir certa textura, ubíqua no álbum, que sugere um mundo que range (não a rede), que entra em curto, que sobeja, um mundo de excesso de coisas, que, recuperadas da condição de badulaques, tornam-se instrumentos musicais nas mãos dos artistas.

A diferença de proposta entre esses três cancionistas e a acalantada canção que principia Chico é flagrante. Mesmo tratando do congelamento da vida presente, que toma forma num "Querido diário", a entoação é conduzida sem fios soltos e a completude de sua composição corresponde a um mundo que ainda faz sentido, que ainda pode ganhar forma coerente.

Recupero esses artistas mais recentes menos para apontar que eventualmente pertençam a um grupo comum - aliás, friso que eles não pertencem a um mesmo movimento, como também não percorrem

30 Em audição comentada do álbum Antes que tu conte outra, pertencente ao Núcleo de Estudos da Canção (UFRGS), a 20 de maio de 2014, o guitarrista Felipe Zancanaro definiu a técnica como a provocação deliberada de um curto-circuito em instrumentos eletrônicos. Definição que vem a calhar para o argumento. 
os mesmos espaços da atual cena musical - e mais para flagrar uma interessante conjuntura: se os artistas são aqueles que representam na forma estética as vicissitudes de seu tempo, e isso vale mesmo em contexto pré-romântico, já que são sensíveis as decantações subjetivas nos modelos quando estes eram seguidos à risca, me parece que temos diferenças consideráveis na representação do nosso tempo a partir da voz desses "novos cancionistas" e da voz de dois dos maiores cancionistas de nossa história recente.

A síntese que ora vislumbro é razoavelmente a seguinte.

Busquei argumentar que a dicção recente de Chico Buarque se move, a partir da herança de "intérprete do Brasil", como uma voz que se encontra na universalidade dos grandes temas, mas de uma perspectiva bastante delimitada, a de um homem demasiado maduro ou velho, que olha para as coisas num misto de enfado, perplexidade, reverência à tradição e medo da morte. Sendo mestre do gênero, suas canções são geralmente perfeitas. No entanto, é possível identificar os desacertos (sempre profícuos para a análise) da revisão histórica e o assombro diante das novidades nas esferas dos afetos e da moral. Ousando um pouco, a voz de Chico envelheceu e agora usufruímos das delícias e das limitações desta nova perspectiva. Esteticamente, um grande sinal de amadurecimento do artista.

Por sua vez, a dicção recente de Caetano Veloso insiste em reconstruir obsessivamente a imagem do maestro da novidade e da vanguarda. Pode-se argumentar que esta busca pela inovação seja um imperativo em seu trabalho, como afirmou Tatit: mesmo recuperando a tradição, Caetano o faz em contracorrente, almejando a diferença. Contudo, ensaiei aqui as contradições dessa atitude estética e o quanto o cancionista mais obedece, atualmente, aos ditames da indústria cultura do que os subverte. A presença destacada de um tropicalismo reificado - mobilizado como coisa, fórmula, e não mais como decantação de dinâmicas importantes do processo social ${ }^{31}$ - e de um eu sempre jovem, ídolo de ouro com ares de fetiche, apontam nesse sentido. Tal como Chico, é um mestre do gênero e trabalha sempre em grau premiado e "premiável"

31 Em artigo anterior, mas ainda no prelo, "Tropicalismo: crítica \& história", disserto especificamente a respeito deste aspecto. 
de excelência (o Grammy por seu recente trabalho não deixa dúvidas a respeito).

Distantes desses dois e distantes entre si, três cancionistas se incumbem de interpretar seu tempo a partir de uma posição menos confortável materialmente e sem sofrerem peso análogo da própria produção no momento criativo: Siba, Juçara Marçal e Apanhador Só. O primeiro, jovem mestre pernambucano de maracatu, mobiliza o rigoroso esquema poético de sua formação para construir belas imagens e uma sensação geral de desencanto. Juçara Marçal, por sua vez, a menos "iniciante" do grupo, se move a partir do que há de melhor na nova cena da música paulistana, com arranjos exigentes, sinceridade de interpretação e belas canções para forjar um mundo em desconcerto para uma voz lírica e combativa. Por fim, a Apanhador Só acusa o sucateamento - físico, moral, ideológico, representativo - de seu entorno por meio de uma sonoridade estridente e na consistente tradição do rock gaúcho, que mantém dicção própria e peculiar desde a banda Liverpool, nos anos 1960.

Não creio que sejam mestres no ofício como os dois cancionistas canônicos, ou seja, pela definição adotada, mesmo numa dicção de arestas, ainda é possível perceber certos impasses. Algumas canções de Siba são amarradas pelo rígido esquema de rimas seguido pelo cancionista, conferindo-lhe aspecto um tanto parnasiano. O álbum de Juçara Marçal, por sua vez, pode ser demasiado cerebral em algumas passagens - a canção "E o Quico?” (Itamar Assumpção) parece tão deslocada quanto a gíria usada em má hora de "Tipo um baião", em Chico. Por fim, o disco da Apanhador Só sofre de uma ausência rematada de auto-ironia ou ceticismo em relação à própria posição que enuncia os problemas dos outros - talvez pela profunda identificação entre os protestos e essa posição satírica e acusatória, o som da banda tenha se tornado trilha sonora e sido escolhido para compor o clipe não oficial das manifestações de junho de 2013.

A despeito dessas limitações, gostaria de frisar o quanto destoam o mundo representado por Chico e Caetano, de um lado, e o mundo representado por Siba, Juçara Marçal e Apanhador Só, de outro. Creio que não seja disparatado pensar que esta conjuntura relativamente nova dos grandes cancionistas de há quarenta, cinquenta anos, que seguem produzindo provocou configurações inéditas para a cena contemporânea da canção popular brasileira. Os filhos de Sérgio Buarque e Dona Canô, não entre si, precisam lidar com o que significam para a canção popular brasileira e seguir criando em cotejo com essa posição moldada por suas trajetórias. Ambos seguem elaborando obras-primas a partir da 
imensidão de suas humanidades, ambos soçobram de maneira diversa na arte de sobreviverem a si mesmos. Complementarmente, talentosos e relativamente desobrigados de estar à altura do que foram, novos cancionistas acusam um mundo em ruína e propõem alternativas a essa desintegração, só de longe sentida pelos já bem postos Chico e Caetano.

Se em "O império da lei”, em Abraçaço, Caetano Veloso comenta o midiático assassinato de Dorothy Stang - "Quem matou, meu amor, tem que pagar / E ainda mais quem mandou matar" -, em "Damião" (Douglas Germano \& Everaldo Ferreira da Silva), em Encarnado, Juçara Marçal canta o caso quase desconhecido do doente mental espancado e tratado com negligência pela Casa de Repouso Guararapes, em Sobral (CE) “Dá neles, Damião! / Dá sem dó nem piedade / E agradece a bondade / E o cuidado de quem te matou".

Não quero aqui validar o dogma de que cabe aos novos artistas cantar o mundo e aos velhos artistas, os grandes temas, mas é interessante como a maturação do campo da canção popular brasileira modificou de fato a posição de onde cantam seus atores, suas visadas e suas questões. A indústria cultural, ora a pleno vapor na canção popular brasileira, age transformando profundamente a dicção de seus principais cancionistas, seja a maneira como são produzidas, seja a maneira como são recebidas. No limite, talvez possamos pensar na ascensão social como uma estratégia sutil, mas muito eficiente, do mercado para calar seus artistas magistrais sobre os aspectos ou tensões mais candentes.

Se este ensaio foi mesmo um salto no abismo, o impacto derradeiro seria um tempo em que os todos os cancionistas fossem rastreados, contatados, contratados e remunerados quase de imediato por um mercado que financia elucra com as mais talentosas vozes dissonantes, amenizando-as. O inferno ou o céu que disso decorrem depende das crenças de cada um.

\section{Sobre o autor}

\section{Carlos Augusto Bonifácio Leite}

Professor Adjunto de Literatura Brasileira na UFRGS. Graduado em Linguística pela Unicamp, especialista, mestre e doutor em Literatura Brasileira pela UFRGS. Compõe a comissão organizadora do Núcleo de Estudos da Canção Popular (UFRGS). É também escritor e cancionista. E-mail: guto.leite82@gmail.com 